\title{
Enhanced Efficiency and Stability of Planar Perovskite Solar Cells Using a Dual Electron Transport Layer of Gold Nanoparticles Embedded in Anatase $\mathrm{TiO}_{2}$ Films
}

\author{
Da-Wei Zhao," Ming-Yu Yu," Ling-Ling Zheng," Ming Li, Shi-Jie Dai, Di-Chun Chen, Tung-Chun Lee,* \\ and Da-Qin Yun*
}

Cite This: ACS Appl. Energy Mater. 2020, 3, 9568-9575

Read Online

ABSTRACT: Incorporating plasmonic nanostructures is a promising strategy to enhance both the optical and electrical characteristics of photovoltaic devices via more efficient harvesting of incident light. Herein, we report a facile fabrication scheme at low temperature for producing gold nanoparticles embedded in anatase $\mathrm{TiO}_{2}$ films, which can simultaneously improve the efficiency and stability of $\mathrm{n}-\mathrm{i}-\mathrm{p}$ planar heterojunction perovskite solar cells (PSCs). The PSCs based on rigid and flexible substrates with 0.2 wt \% $\mathrm{Au}-$ $\mathrm{TiO}_{2} / \mathrm{TiO}_{2}$ dual electron transport layers (ETLs) achieved power conversion efficiencies up to 20.31 and $15.36 \%$, superior to that of devices with $\mathrm{TiO}_{2}$ as a single ETL. Moreover, 0.2 wt $\% \mathrm{Au}-\mathrm{TiO}_{2} / \mathrm{TiO}_{2}$ devices demonstrated significant stability in light soaking, which is attributed to improved light absorption, low charge recombination loss, and enhanced carrier transport, and extraction with the plasmonic $\mathrm{Au}-\mathrm{TiO}_{2} / \mathrm{TiO}_{2}$ dual ETL. The present work

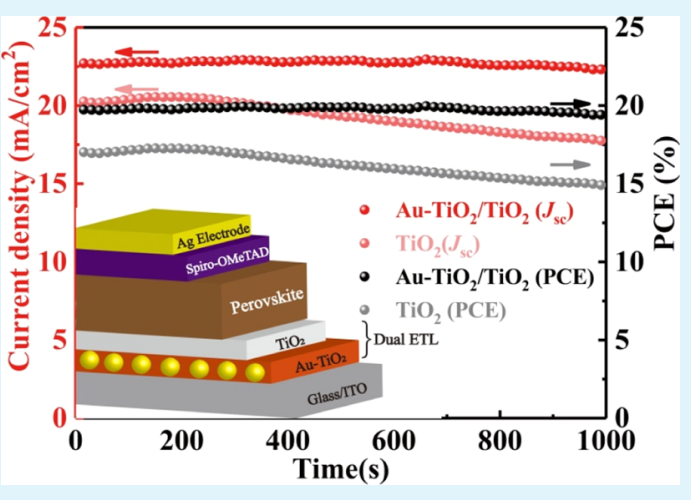
improves the practicability of high-performance and flexible PSCs by engineering the photogenerated carrier dynamics at the interface.

KEYWORDS: perovskite solar cell, electron selective layer, low-temperature solution process, plasmonic nanostructure, flexible solar cell

\section{INTRODUCTION}

Perovskite solar cell (PSC) is one of the key technologies in developing modern electronic devices because of its high power conversion efficiency (PCE > 25\%), good flexibility, affordable costs, simple solution-based fabrication process, and potential application for scalable products. ${ }^{1,2}$ However, so far, the poor long-term stability of PSC still hinders its commercialization. ${ }^{3,4}$ The instability issues of PSC are mainly due to the low chemical stability of organic-inorganic hybrid perovskite materials upon exposure to external environments, such as moisture, oxygen, temperature, light soaking, and electrical biasing. ${ }^{5,6}$ In this context, various methods have been developed to address these problems. ${ }^{7-9}$ Interface modification has been proven to enable PSC working more stable and more efficiently. Perovskite crystal growth can be controlled to tune the film morphology for regulating ion migration and the density of trap states, resulting in a reduction in carrier recombination and the charge transfer/extraction barrier. ${ }^{10-12}$ In particular, a significant amount of effort has been focused on reducing ions transportation in the perovskite layers, ${ }^{13-15}$ modifying the electron and hole selective layers, ${ }^{16-18}$ as well as blocking the reactions between metal electrodes and halides. ${ }^{19}$

Compared to the conventional methods, incorporating plasmonic nanostructures, as a novel interfacial tailoring technique, has been proven to enhance the PCE of PSCs more efficiently because it possesses broadly tunable optical properties coupled with photovoltaic active surfaces that simultaneously benefit photon energy and electron management. ${ }^{20-22}$ Moreover, it is noteworthy that gold nanoparticles (Au NPs) exhibit both high thermal stability and high chemical stability, as well as localized surface plasmon resonance (LSPR) in the visible-to-near-infrared (vis-NIR) range. The resulted near- and far-optical field effects can produce intense absorption, scattering, and significantly enhanced electromagnetic (EM) fields in the nanoscale vicinity of their surface, which have a sensitive dependence on the size, shape, and dielectric environments of NPs. ${ }^{23}$ It can be seen that the dielectric environment of Au NPs plays an essential role in optimizing the EM field distribution of LSPR, which will further influence the charge carrier dynamics and free carrier absorption in photovoltaic materials. ${ }^{24}$ For instance, in 2013,

Received: February 9, 2020

Accepted: September 14, 2020

Published: September 14, 2020 
(a)
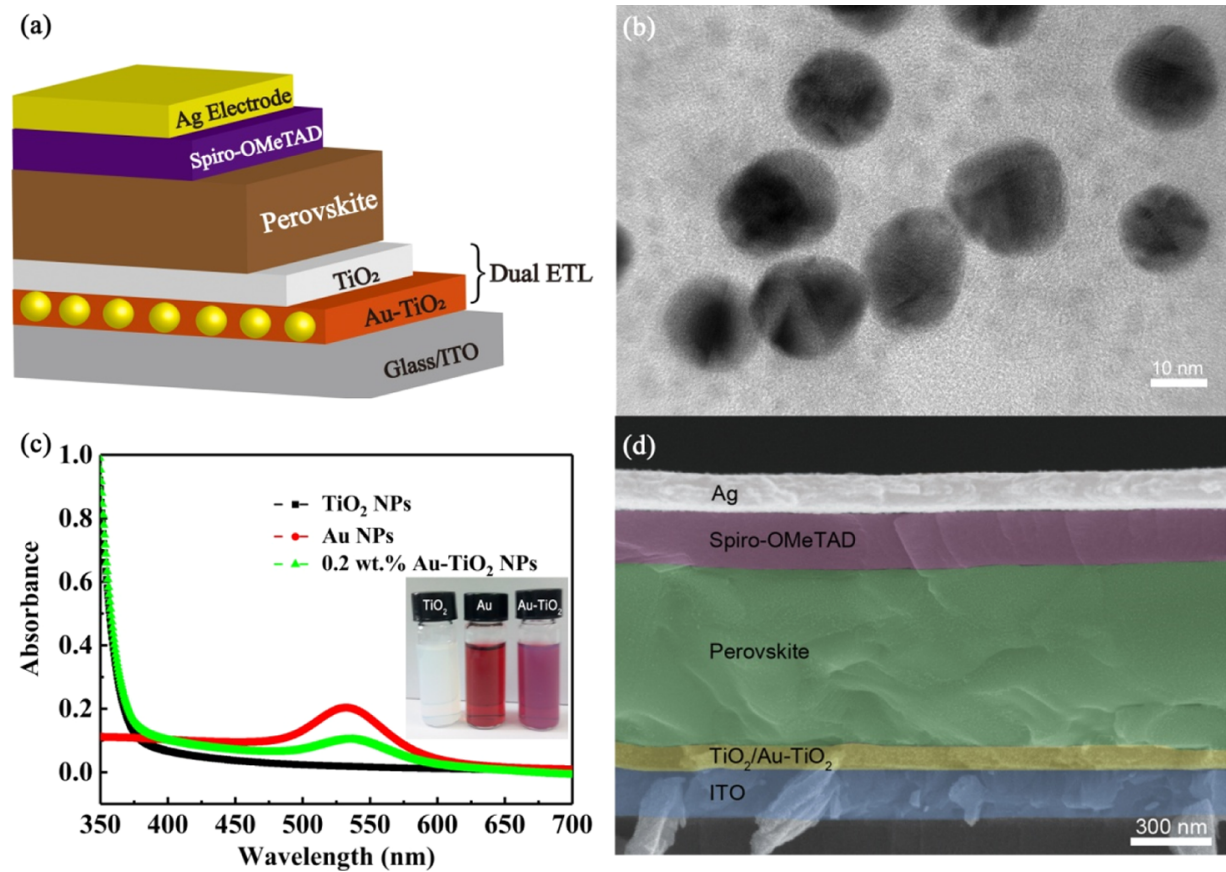

Figure 1. (a) Schematic diagram showing the device configuration. (b) TEM image of 0.2 wt $\% \mathrm{Au}-\mathrm{TiO}_{2} \mathrm{NPs}$. (c) $\mathrm{Absorption}$ of $\mathrm{TiO} \mathrm{N}_{2} \mathrm{NPs}, \mathrm{Au}$ $\mathrm{NPs}$, and $0.2 \mathrm{wt} \% \mathrm{Au}-\mathrm{TiO}_{2} \mathrm{NPs}$ composite solutions with inset showing the photographs of the three solutions. (d) Cross-sectional SEM image of the internal structure in the PSC.

Snaith reported for the first time the introduction of $\mathrm{Au} @ \mathrm{SiO}_{2}$ core-shell NPs into an $\mathrm{Al}_{2} \mathrm{O}_{3}$ matrix. Such a modified electron transport layer (ETL) succeeded in improving the performance of PSCs by plasmonic effects. The improvement was caused by a decrease in the exciton binding energy of perovskite materials; however, the light absorption was not increased. ${ }^{25}$ Subsequently, these features have been extensively studied by the introduction of various dielectric coatings into PSC configurations, such as $\mathrm{SiO}_{2},{ }^{26,27} \mathrm{TiO}_{2}{ }^{28-30}$ and $\mathrm{MgO}$, ${ }^{31}$ in which $\mathrm{Au}$ NPs have been interfaced with $\mathrm{TiO}_{2}$ to maximize the charge separation of hot electrons. ${ }^{24,32}$ Although these plasmonic nanostructures have demonstrated some promise in the efficiency enhancement of PSCs by plasmonic effects, there is rare research in investigating the low-temperature solutionprocessed plasmonic nanostructures of the Au NPs embedded in anatase $\mathrm{TiO}_{2}$ films, especially for their application in flexible PSCs.

Herein, we apply facile interface engineering to create plasmonic nanostructures of $\mathrm{Au}$ NPs embedded in anatase $\mathrm{TiO}_{2}$ layers, where the $\mathrm{Au} \mathrm{NPs}$ and the anatase $\mathrm{TiO}_{2} \mathrm{NPs}$ are prepared in aqueous media and the $\mathrm{Au}-\mathrm{TiO}_{2} / \mathrm{TiO}_{2}$ dual ETLs are directly deposited from aqueous solutions containing various weight ratios of $\mathrm{Au} \mathrm{NPs}$ and $\mathrm{TiO}_{2} \mathrm{NPs}$. Based on the $\mathrm{n}-\mathrm{i}-\mathrm{p}$ structure of $\mathrm{ITO} / 0.2$ wt $\% \mathrm{Au}-\mathrm{TiO}_{2} / \mathrm{TiO}_{2} /(\mathrm{HC}$ $\left.\left(\mathrm{NH}_{2}\right)_{2} \mathrm{PbI}_{3}\right)_{x}\left(\mathrm{CH}_{3} \mathrm{NH}_{3} \mathrm{PbCl}_{3}\right)_{1-x} /$ spiro-OMeTAD/Ag, the photovoltaic performance of PSCs can be rationalized by optimizing the physical properties of the ETL and the interface between the ETL and perovskite layer. With the help of $\mathrm{Au}$ NPs, the highest PCE of the PSCs on rigid and flexible substrates can reach 20.31 and $15.36 \%$, respectively, superior to that of devices with $\mathrm{TiO}_{2}$ as a single ETL (champion PCE = $17.19 \%$ on a rigid substrate and champion PCE $=12.80 \%$ on a flexible substrate). Moreover, the devices based on plasmonic nanostructures demonstrate improved stability in light soaking compared to those using a pure $\mathrm{TiO}_{2}$ film as an ETL, which is attributed to the higher light absorption efficiency, improved interface charge transfer rate, and reduced recombination loss, as supported by our stable external quantum efficiency (EQE), the significant fluorescence quenching in photoluminescence (PL) measurements and electrochemical impedance spectroscopy (EIS) data.

\section{EXPERIMENTAL SECTION}

2.1. Materials and Synthesis. $\mathrm{TiO}_{2} \mathrm{NPs}$ were synthesized from the sol-gel way according to the previous research. ${ }^{33}$ Titanium(IV) isopropoxide was dropped into deionized water mixed with nitric acid accompanied with intense stirring. Then after hydrolysis, it formed a white $\mathrm{TiO}_{2} \mathrm{NPs}$ colloid; the colloid was heated to $80{ }^{\circ} \mathrm{C}$ meanwhile stirred intensely, to produce the $\mathrm{TiO}_{2} \mathrm{NPs}\left(20 \mathrm{mg} \mathrm{mL}{ }^{-1}\right)$. Last, the $\mathrm{TiO}_{2}$ NPs needed to be filtered using a $0.45 \mu \mathrm{m}$ polyvinylidene fluoride syringe filter.

$\mathrm{Au}$ NPs were synthesized according to the procedures described in the literature. ${ }^{34} \mathrm{HAuCl}_{4} \cdot 3 \mathrm{H}_{2} \mathrm{O}(99.9 \%)$ and sodium citrate dihydrate (99\%) were both purchased from Sigma-Aldrich. Typically, $1 \mathrm{~mL}$ of $60 \mathrm{mM}$ sodium citrate and $1 \mathrm{~mL}$ of a $25 \mathrm{mM} \mathrm{HAuCl}_{4}$ solution were sequentially injected into $50 \mathrm{~mL}$ of a vigorously boiling $2.2 \mathrm{mM}$ sodium citrate aqueous solution. Boiled this mixture for $15 \mathrm{~min}$ and then continued stirring for another $15 \mathrm{~min}$. The yielded Au seed solution needed to be cooled down to $90{ }^{\circ} \mathrm{C}$. After that, $1 \mathrm{~mL}$ of sodium citrate $(60 \mathrm{mM})$ and $1 \mathrm{~mL}$ of a $\mathrm{HAuCl}_{4}$ solution $(25 \mathrm{mM})$ were injected sequentially. The reaction lasted for about $30 \mathrm{~min}$. By repeating this operation (sequential injection of $1 \mathrm{~mL}$ of $60 \mathrm{mM}$ sodium citrate and $1 \mathrm{~mL}$ of $25 \mathrm{mM} \mathrm{HAuCl}$ ), the sizes of Au NPs grew progressively, cooled the resulting $\mathrm{Au} \mathrm{NPs}$ solution to room temperature, filtered then stored it under $4{ }^{\circ} \mathrm{C}$.

2.2. Fabrication. Before being used, ITO required ultrasonic cleaning. The $\mathrm{Au}-\mathrm{TiO}_{2} \mathrm{NPs}$ solution was prepared by adding different amounts of $\mathrm{Au}$ NPs into the as-synthesized $\mathrm{TiO}_{2} \mathrm{NPs}$ solution at the loading ratio from 0.1 to $0.3 \mathrm{wt} \%$. The $\mathrm{Au}-\mathrm{TiO}_{2} \mathrm{NPs}$ and $\mathrm{TiO}_{2} \mathrm{NPs}$ solutions ( $20 \mathrm{mg} \mathrm{mL} \mathrm{m}^{-1}$ for both solutions) were sequentially coated by spinning at $4000 \mathrm{rpm}$ for $40 \mathrm{~s}$, afterward, annealed at $150{ }^{\circ} \mathrm{C}$ for $1 \mathrm{~h}$. To form a perovskite film, the preparation method for $\mathrm{PbI}_{2}$ [dimethylsulfoxide (DMSO)] complex based on a 
(a)

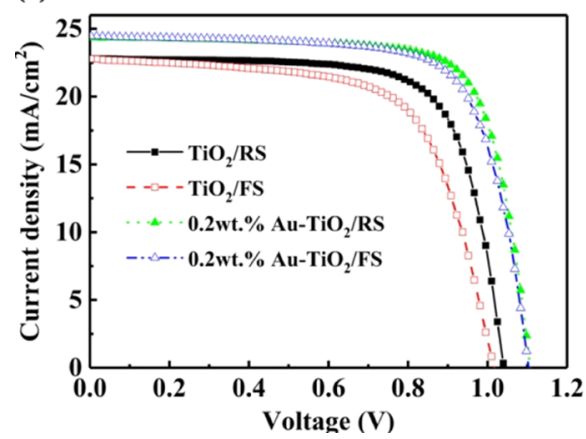

(b)

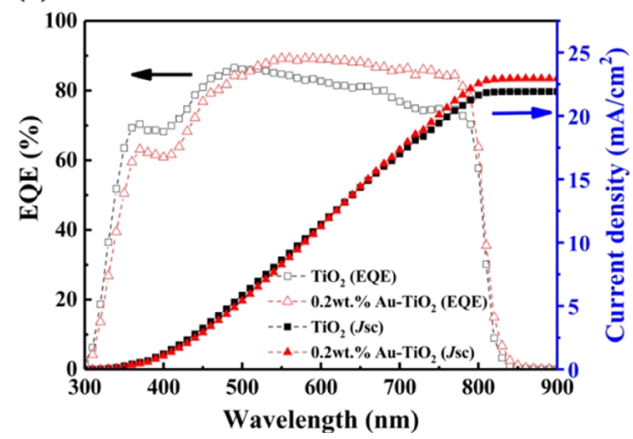

Figure 2. (a) Champion $J-V$ curves and (b) EQE plots of the PSCs.

previous report was applied. ${ }^{35}$ Formamidinium iodide (FAI) and methylamine chloride (MACl) were prepared in a typical way according to former research. ${ }^{36}$ The $1.5 \mathrm{M} \mathrm{PbI}_{2}$ (DMSO) complex dissolved in DMF was coated by spinning at $2500 \mathrm{rpm}$ for $40 \mathrm{~s}$. Subsequently, spin-coated the FAI/MACl mixture $\left(70 \mathrm{mg} \mathrm{mL}^{-1}\right)$ with $2500 \mathrm{rpm}$ for $40 \mathrm{~s}$. Then, annealed at $120^{\circ} \mathrm{C}$. Cooling down to room temperature, then deposited spiro-OMeTAD at $2000 \mathrm{rpm}$ for $40 \mathrm{~s}$ to form a hole transport layer. The spiro-OMeTAD solution was made by dissolving spiro-OMeTAD into chlorobenzene $(60 \mathrm{mM})$ with 30 $\mathrm{mM} \mathrm{Li}$-TFSI ( $520 \mathrm{mg} \mathrm{mL}^{-1}$ in acetonitrile), $200 \mathrm{mM} \mathrm{4-tBP}$, and 1.8 mM FK209 (300 mg mL ${ }^{-1}$ in acetonitrile). Eventually, a $100 \mathrm{~nm}$ of silver electrode with an active area of $0.1 \mathrm{~cm}^{2}$ was made through thermal evaporation with the help of a mask to pattern the electrode. To fabricate flexible PSCs, the only different thing was to use patterned ITO-PEN substrates with a $0.06 \mathrm{~cm}^{2}$ active area.

2.3. Characterization. The structure and morphology were explored by transmission electron microscopy (TEM, JEOL JEM2100) and field-emission scanning electron microscopy (SEM, ZEISS SUPRA 55). The absorbance spectra were tested using an ultraviolet-visible spectrophotometer (UV-vis, UV-2600). Electrical properties of the $\mathrm{Au}-\mathrm{TiO}_{2}$ and $\mathrm{TiO}_{2}$ layers were evaluated by the PL (F-7000) and time-resolved PL (TRPL, FLS-980) spectra. The current density-voltage $(J-V)$ curves were tested by the Keithley 2400 source meter under 1 sun illumination (AM 1.5 G, $100 \mathrm{~mW}$ $\mathrm{cm}^{-2}$ ). Unless otherwise noted, the devices were tested in the forward and reverse scan with a $20 \mathrm{~ms}$ dwell time. The hysteresis index was calculated according to a previously reported formula to quantify the hysteresis effect of PSCs. ${ }^{37}$ The external quantum efficiency (EQE) spectra was tested via the EQE system (Newport). The EIS was tested via the VersaSTAT 3. The stabilized-efficiency measurement was tested via the CHI660E.

\section{RESULTS AND DISCUSSION}

3.1. Composition and Structure. We prepared Au NPs via a low-temperature fabrication scheme and embedded them into $\mathrm{TiO}_{2}$ films to make $\mathrm{Au}-\mathrm{TiO}_{2}$ films function as ETLs. The $\mathrm{TiO}_{2}$ film is composed of nanocrystalline anatase $\mathrm{TiO}_{2} \mathrm{NPs}$ prepared using a low-temperature solution-based approach developed by us previously. ${ }^{34}$ Their small and uniform particle morphology facilitates the incorporation of Au NPs within the ETL matrix and allow fine control over the ETL thickness.

To maximize the LSPR effect of $\mathrm{Au} \mathrm{NPs}$ and thus to maximize the light-harvesting ability of the active layer, the $\mathrm{Au}$ NPs should be close to or dispersed well into the perovskite layer. However, the perovskite film in immediate contact with the metallic nanoparticles will lead to rapid charge recombination and excitons quenching. ${ }^{38}$ Thus, in order to avoid the adverse effects, the $n-i-p$ PSCs were composed of ITO/Au$\mathrm{TiO}_{2} / \mathrm{TiO}_{2} /\left(\mathrm{FAPbI}_{3}\right)_{x}\left(\mathrm{MAPbCl}_{3}\right)_{1-x} /$ spiro-OMeTAD $/ \mathrm{Ag}$ in this work (Figure 1a). In particular, a dual ETL of $\mathrm{Au}-$ $\mathrm{TiO}_{2} / \mathrm{TiO}_{2}$ was employed and optimized to minimize energy losses, while maximizing the plasmonic effects on both the ETL and the perovskite layer.

A schematic of plasmon-induced charge transport was provided to understand the impact of Au NPs on the PSCs in detail, as shown in Figure S1. On one hand, the far-field effect of Au NPs acts as the scattering substance can increase the light travel distance in perovskite, which can effectively improve the absorption of photons of the active layer; on the other hand, the near-field effect can facilitate more hot electrons into the conduction band of ETL, thereby enhancing the charge transport and collection of pure $\mathrm{TiO}_{2}$.

Also, the electrical conductivity of different ETLs (Figure S2) is studied according to the methods reported in the previous literature. ${ }^{39,40}$ The active area and thickness of all samples will be the same, so we can determine the electrical conductance of each ETL from the $I-V$ curve slope. The conductivity of ETLs rises progressively with the content of the metallic $\mathrm{Au}$ NPs, which implies that $\mathrm{Au}-\mathrm{TiO}_{2}$ ETLs have stronger charge transport capability.

The morphologies of the as-prepared Au NPs and 0.2 wt \% $\mathrm{Au}-\mathrm{TiO}_{2} \mathrm{NPs}$ are shown in Figures $\mathrm{S} 3$ and $1 \mathrm{~b}$, respectively. The Au NPs $(16 \pm 2 \mathrm{~nm})$ are uniformly dispersed and embedded into the $\mathrm{TiO}_{2}$ matrix. The selected area electron diffraction pattern (Figure S3, inset) shows typical electron diffraction rings corresponding to the (111), (200), (220), and (311) lattice planes of the crystal structure of $\mathrm{Au}$, consistent to the reported results. ${ }^{41}$ Figure $1 \mathrm{c}$ and the inset show typical sample solutions of $\mathrm{TiO}_{2} \mathrm{NPs}, \mathrm{Au} \mathrm{NPs}$, and the $0.2 \mathrm{wt} \% \mathrm{Au}-$ $\mathrm{TiO}_{2}$ NPs in water, as well as their corresponding UV-vis extinction spectra. Both the Au NPs and the $0.2 \mathrm{wt} \% \mathrm{Au}-$ $\mathrm{TiO}_{2}$ NPs exhibit a deep red color with a maximum absorption peak at $527 \mathrm{~nm}$ owing to the LSPR property of the Au NPs. ${ }^{23}$ The UV-vis transmittance spectra of different ETLs is shown in Figure S4; however, the 0.2 wt \% $\mathrm{Au}-\mathrm{TiO}_{2} \mathrm{NPs}$ thin film hardly changed in transmittance between 400 and $800 \mathrm{~nm}$. The result shows that the introduction of Au NPs causes only a slight decrease of transmittance in the ultraviolet region.

Indeed, the photovoltaic device characteristics is strongly dependent on perovskite film properties. A desirable $\left(\mathrm{FAPbI}_{3}\right)_{x}\left(\mathrm{MAPbCl}_{3}\right)_{1-x}$ perovskite layer displayed in the SEM image exhibited compact and highly crystalline morphology, which can facilitate charge transfer and inhibit grain-boundary charge recombination.

3.2. Rigid Devices. To investigate the effects of incorporating $\mathrm{Au}$ NPs within the ETL, we prepared the ETLs containing various weight ratios of $\mathrm{Au}-\mathrm{TiO}_{2}(0,0.1,0.2$, and $0.3 \mathrm{wt} \%)$, see Figure $S 5$ for the measured $J-V$ curves and Table S1 for photovoltaic parameters. According to the 
Table 1. Photovoltaic Parameters

\begin{tabular}{|c|c|c|c|c|c|c|c|}
\hline ETL & substrate & scanning direction $^{a}$ & $V_{\mathrm{OC}}[\mathrm{V}]$ & $J_{\mathrm{SC}}\left[\mathrm{mA} \mathrm{cm} \mathrm{cm}^{-2}\right]$ & $\mathrm{FF}[\%]$ & PCE $[\%]$ & hysteresis index \\
\hline \multirow[t]{2}{*}{$\mathrm{TiO}_{2}$} & ITO-glass & F (champion) & 1.02 & 22.81 & 65.68 & 15.23 & 0.11 \\
\hline & ITO-glass & $\mathrm{R}$ (champion) & 1.04 & 22.79 & 72.52 & 17.19 & \\
\hline \multirow[t]{2}{*}{0.2 wt $\% \mathrm{Au}-\mathrm{TiO}_{2} / \mathrm{TiO}_{2}$} & ITO-glass & F (champion) & 1.10 & 24.49 & 72.67 & 19.62 & 0.03 \\
\hline & ITO-glass & R (champion) & 1.11 & 24.36 & 75.33 & 20.31 & \\
\hline
\end{tabular}

${ }^{a} \mathrm{R}$ indicates reverse scanning directions.
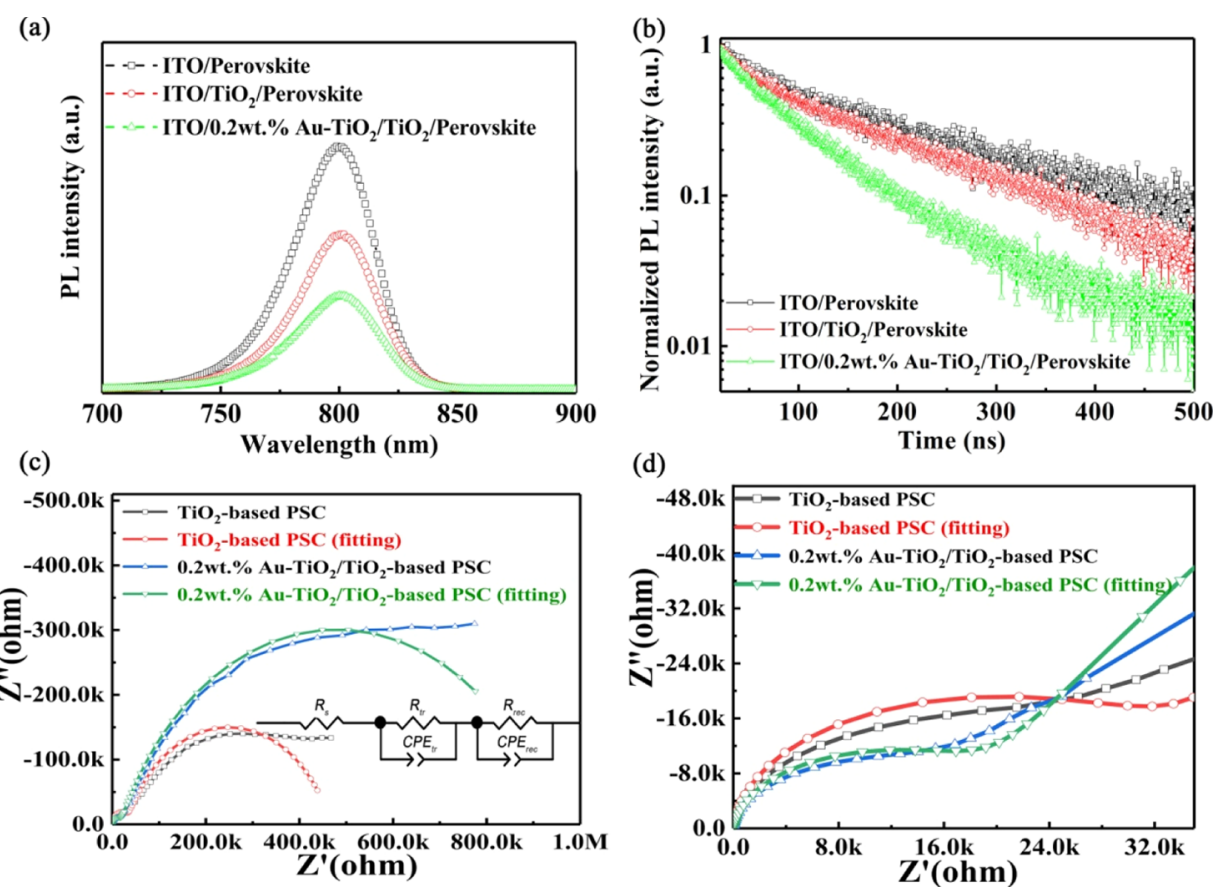

Figure 3. (a) Steady-state and (b) TRPL spectra. (c) Nyquist plots with inset showing the equivalent circuit model for the PSCs in EIS. (d) Magnification of the high-frequency region of Nyquist plots of PSCs.

statistical results (Figure S7) from 20 identical $\mathrm{Au}-\mathrm{TiO}_{2} /$ $\mathrm{TiO}_{2}$-based devices, when the concentration of $\mathrm{Au} \mathrm{NPs}$ increased from 0 to 0.2 wt $\% \mathrm{Au}-\mathrm{TiO}_{2}$, the PSC devices showed an increase in the PCE, which may have resulted from the multifunctional Au NPs in anatase $\mathrm{TiO}_{2}$ via enhancing the photocurrent and improve the electrical properties of pure $\mathrm{TiO}_{2}$. However, as the concentration continued to increase, the PCE began to decrease. Such a decline may be attributed to excess recombination centers provided by the excess $\mathrm{Au}$ NPs. Here, the optimal concentration of Au NPs in anatase $\mathrm{TiO}_{2}$ was found to be approximately $0.2 \mathrm{wt} \%$. Interestingly, the device based on a single $\mathrm{Au}-\mathrm{TiO}_{2}$ ETL without the $\mathrm{TiO}_{2}$ top layer exhibits much lower $V_{\mathrm{OC}}$ and $\mathrm{FF}$ than that of the pure $\mathrm{TiO}_{2}$ ETL as well as that of $\mathrm{Au}-\mathrm{TiO}_{2} / \mathrm{TiO}_{2}$ dual ETL, resulting in the lowest PCE (Figure S6 and Table S2). This may be caused by Au NPs embedded in the $\mathrm{TiO}_{2}$ layer that act as charge traps once in direct contact with the perovskite film, leading to an increased rate of interfacial carrier recombination, ${ }^{28,31}$ compared to the $\mathrm{Au}-\mathrm{TiO}_{2} / \mathrm{TiO}_{2}$ dual ETL.

Figure $2 \mathrm{a}$ and Table 1 show the $J-V$ curves and detailed parameters of the rigid PSCs based on the $\mathrm{TiO}_{2} \mathrm{ETL}$ and 0.2 wt $\% \mathrm{Au}-\mathrm{TiO}_{2} / \mathrm{TiO}_{2}$ ETL. In particular, the rigid 0.2 wt $\%$ $\mathrm{Au}-\mathrm{TiO}_{2} / \mathrm{TiO}_{2}$ PSCs exhibit considerably low hysteresis indices $(0.03)$ and show a $J_{\mathrm{SC}}$ of $24.36 \mathrm{~mA} \mathrm{~cm}{ }^{-1}$, a $V_{\mathrm{OC}}$ of $1.11 \mathrm{~V}$, and an FF of $75.33 \%$, corresponding to a high PCE of $20.31 \%$, which shows a significant improvement over that of the control device (hysteresis index $=0.11, \mathrm{PCE}=17.19 \%$ ) using a single $\mathrm{TiO}_{2}$ film as the ETL. The increased PCE and suppressed hysteresis could be due to the plasmonic effects of $\mathrm{Au}$ NPs on the $\mathrm{TiO}_{2}$ ETL, which can promote electrons to transfer into $\mathrm{TiO}_{2}$, leading to an enhancement in the improvement of $V_{\mathrm{OC}}, J_{\mathrm{SC}}$, and $\mathrm{FF}^{42}$

To further confirm the improvement of the light-harvesting ability of the devices with Au NPs, EQE spectra was measured and is shown in Figure 2b. It can be clearly observed that the EQE of the sample with 0.2 wt $\% \mathrm{Au}-\mathrm{TiO}_{2} / \mathrm{TiO}_{2} \mathrm{ETL}$ has an enhancement in (492-850 $\mathrm{nm}$ range) but a small reduction in (350-492 nm range) regions compared to that of the $\mathrm{TiO}_{2}$ ETL, as shown in Figure $2 \mathrm{~b}$. These results may be due to the far field effect that improves the perovskite absorbance in the visible region, and to the near field effect that decreases the $\mathrm{TiO}_{2}$ transmittance, leading to a light reduction reaching the perovskite in the UV region. ${ }^{43}$ The integrated $J_{S C}$ of the PSCs generated from the EQE were 21.92 and $22.95 \mathrm{~mA} \mathrm{~cm}^{-2}$ for $\mathrm{TiO}_{2}$ and 0.2 wt $\% \mathrm{Au}-\mathrm{TiO}_{2} / \mathrm{TiO}_{2}$, respectively. These results indicate that PSCs with $0.2 \mathrm{wt} \% \mathrm{Au}-\mathrm{TiO}_{2} / \mathrm{TiO}_{2}$ ETLs indeed exhibit a plasmonic effect, resulting in increasing the photocurrent. However, LSPR may not be sufficient to explain all improvements in the photovoltaic parameters of the devices. The increase in the EQE in the wavelength range $492-850 \mathrm{~nm}$ can also be partially resulted from enhanced electrical properties in the presence of Au NPs.

3.3. Morphological, Optical, and Electrical Behaviors. The morphology of the substrate may affect the quality of the 
Table 2. Biexponential Decay Dynamics

\begin{tabular}{|c|c|c|c|c|c|}
\hline sample & $\tau_{1}(\mathrm{~ns})$ & $f_{1}(\%)$ & $\tau_{2}(\mathrm{~ns})$ & $f_{2}(\%)$ & $\tau_{\text {ave }}(\mathrm{ns})$ \\
\hline ITO/perovskite & 34.89 & 6.83 & 208.10 & 93.17 & 196.27 \\
\hline $\mathrm{ITO} / \mathrm{TiO}_{2} /$ perovskite & 28.69 & 7.07 & 193.70 & 92.93 & 182.03 \\
\hline ITO $/ 0.2$ wt $\% \mathrm{Au}-\mathrm{TiO}_{2} / \mathrm{TiO}_{2} /$ perovskite & 37.18 & 19.26 & 98.07 & 80.74 & 86.34 \\
\hline
\end{tabular}

Table 3. Fitted Data from the EIS Measurements

\begin{tabular}{|c|c|c|c|c|c|}
\hline ETL & $R_{\mathrm{s}}(\Omega)$ & $R_{\mathrm{tr}}(\Omega)$ & $R_{\mathrm{rec}}(\Omega)$ & $C_{\text {tr }}(\mathrm{F})$ & $C_{\mathrm{rec}}(\mathrm{F})$ \\
\hline $\mathrm{TiO}_{2}$ & 1.688 & $3.009 \times 10^{4}$ & $4.367 \times 10^{5}$ & $9.597 \times 10^{-9}$ & $4.746 \times 10^{-7}$ \\
\hline 0.2 wt $\% \mathrm{Au}-\mathrm{TiO}_{2} / \mathrm{TiO}_{2}$ & 1.542 & $1.645 \times 10^{4}$ & $9.266 \times 10^{5}$ & $9.374 \times 10^{-9}$ & $5.111 \times 10^{-7}$ \\
\hline
\end{tabular}

(a)
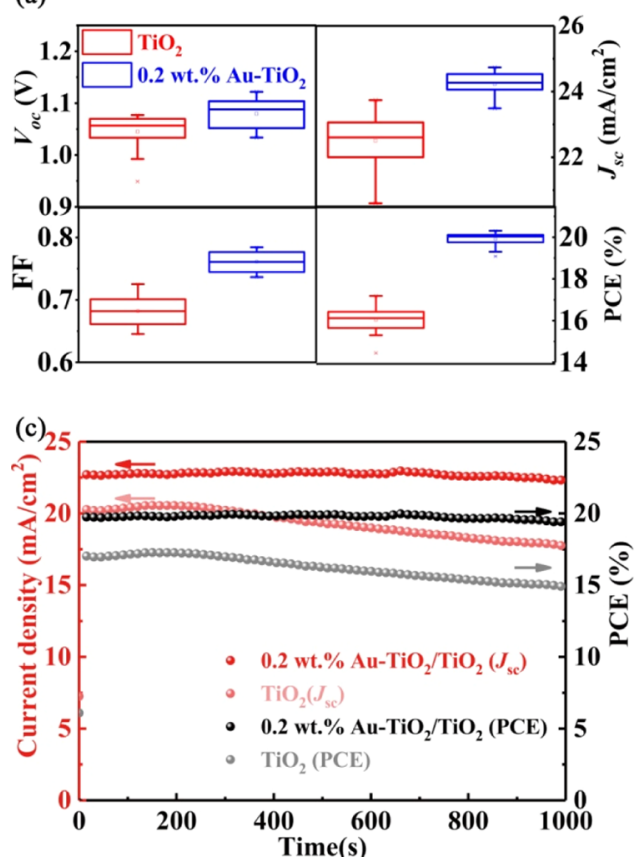

(b)
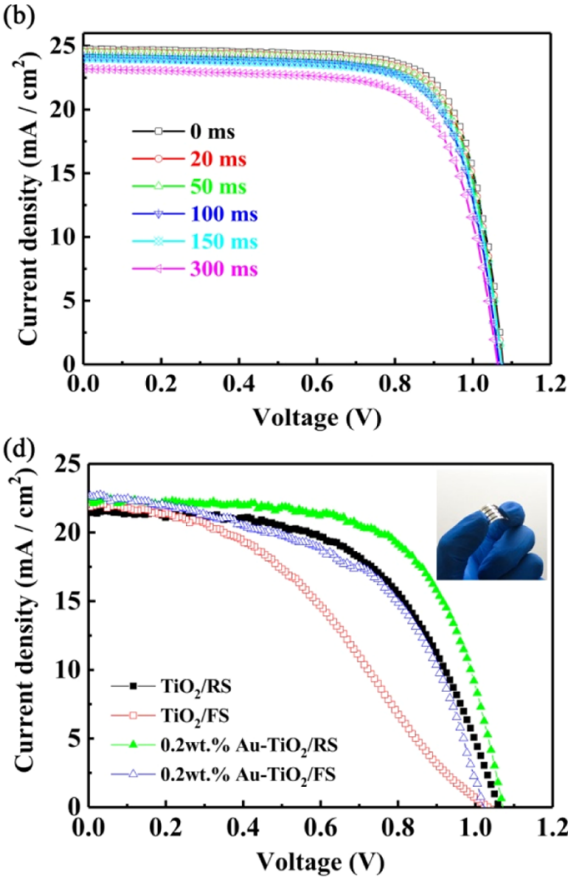

Figure 4. (a) Statistical deviation of the photovoltaic parameters. (b) $J-V$ curves of the PSCs based on 0.2 wt $\% \mathrm{Au}^{-} \mathrm{TiO}_{2} / \mathrm{TiO} \mathrm{ETLs}_{2}$ conducted at different dwell times. (c) Stabilized-efficiency measured at 0.84 and $0.87 \mathrm{~V}$ bias, respectively. (d) $J-V$ curves of the flexible PSCs and the inset shows the prototype of a flexible PSC.

perovskite, so we explored the SEM morphology of different substrates and perovskites based on different substrates, as shown in Figure S8. It can be seen from the figure that the surface morphology of different substrates is very smooth and dense, and there is almost no obvious difference. In addition, the overall perovskite grain size is very uniform, and the perovskite crystals have similar quality.

To obtain insights into the interfacial dynamics of the charge extraction at the ETL/perovskite, we obtained steady-state PL spectra and UV-vis spectra as shown in Figures 3a and S9, respectively. Although the device based on $\mathrm{Au}-\mathrm{TiO}_{2}$ does not show an obvious advantage in the absorption coefficient over the device based on pure $\mathrm{TiO}_{2}$ because the absorption coefficient of the perovskite is much higher than that of $\mathrm{Au}$ $\mathrm{NPs}^{44}$ the increase in the photocurrent generation and the reduction in recombination loss could be further confirmed by PL measurements. The intensity of an emission peak centered at $\sim 800 \mathrm{~nm}$ (Figure $3 \mathrm{a}$ ), is reduced to nearly one-third via the insertion of the $\mathrm{TiO}_{2}$ ETL. Further fluorescence quenching for the ITO/0.2 wt $\% \mathrm{Au}-\mathrm{TiO}_{2} / \mathrm{TiO}_{2} /$ perovskite sample indicates that the metallic $\mathrm{Au}$ NPs modification is beneficial to interfacial charge extraction.
To further study the recombination rate of different devices, TRPL decay spectra is shown in Figure $3 \mathrm{~b}$. It is worth noting that the significant fluorescence quenching for the ITO/0.2 wt $\% \mathrm{Au}-\mathrm{TiO}_{2} / \mathrm{TiO}_{2} /$ perovskite sample is likely caused by the increase in electrical conductance of the ETL and more efficient charge extraction provided by the metallic Au NPs. Compared to those of the ITO/perovskite (196.27 ns) and the $\mathrm{ITO} / \mathrm{TiO}_{2} /$ perovskite $(182.03 \mathrm{~ns}), \mathrm{PL}$ quenching of the ITO/ 0.2 wt $\% \mathrm{Au}-\mathrm{TiO}_{2} / \mathrm{TiO}_{2} /$ perovskite sample exhibits the fastest decay time of 86.34 ns (Table 2), which implies that radiative electron-hole recombination is suppressed and hence improves the performance of the devices via the enhanced light harvesting capability.

In addition to optical characterization, EIS measurements were performed in a dark environment to investigate the interfacial electrical dynamics. Figure $3 \mathrm{c}$ shows the Nyquist plots for the PSCs based on $\mathrm{TiO}_{2}$ and $\mathrm{Au}-\mathrm{TiO}_{2} / \mathrm{TiO}_{2}$ tested at a voltage bias of $0.4 \mathrm{~V}$. Typically, in the Nyquist plot, the high frequency arc is controlled by charge transport kinetics, while the low frequency arc is controlled by charge recombination processes. $^{45}$ For a clearer view, Figure $3 \mathrm{~d}$ shows the zoom-in of the high-frequency region. The fitted equivalent circuit model (inset of Figure 3c) mainly contains 
three electrical components: series resistance $\left(R_{\mathrm{s}}\right)$, transport $\left(R_{\mathrm{tr}}\right)$ in parallel with the constant phase angle element $\left(\mathrm{CPE}_{\mathrm{tr}}\right)$, and recombination $\left(R_{\text {rec }}\right)$ parallel in parallel with another element $\left(\mathrm{CPE}_{\mathrm{rec}}\right){ }^{46} R_{\mathrm{tr}}$ and $R_{\text {rec }}$ are typically related to the high-frequency arc and the low-frequency arc, respectively. As shown in Table 3, the $R_{s}$ value of the PSC based on $0.2 \mathrm{wt} \%$ $\mathrm{Au}-\mathrm{TiO}_{2} / \mathrm{TiO}_{2}$ is slightly lower than the pristine $\mathrm{TiO}_{2}$-based PSC. Compared to the control device, the $R_{\mathrm{tr}}$ and $R_{\mathrm{rec}}$ values of the PSC based on 0.2 wt $\% \mathrm{Au}-\mathrm{TiO} / \mathrm{TiO}_{2}$ are reduced by $45 \%$ and enhanced by $112 \%$, indicating that the $\mathrm{Au}-\mathrm{TiO}_{2}$ interlayer decreases charge recombination loss.

3.4. Stability of Devices. We prepared a series of cells under the same conditions to test the stability and reproducibility of the PSCs. Statistical data based on 20 cells illustrates the reproducibility and uniformity of the PSC performance, as shown in Figure $4 \mathrm{a}$. The $J-V$ curves of the $\mathrm{Au}-\mathrm{TiO}_{2} / \mathrm{TiO}_{2}$-based PSCs exhibit excellent stability of current hysteresis over a wide range of dwell time (0-300 $\mathrm{ms}$ ), as shown in Figure $4 \mathrm{~b}$. Also, the stabilized photocurrent was measured at a constant bias of 0.84 and $0.87 \mathrm{~V}$, respectively, to test the light-soaking stability of devices. As shown in Figure $4 c$, a maximal steady-state $J_{\mathrm{SC}}$ of the $\mathrm{TiO}_{2}$ based and 0.2 wt $\% \mathrm{Au}-\mathrm{TiO}_{2}$-based PSCs is 20.51 and 22.93 $\mathrm{mA} \mathrm{cm}{ }^{-2}$, with a corresponding PCE of 17.23 and $19.95 \%$, respectively. Additionally, devices based on 0.2 wt \% Au$\mathrm{TiO}_{2} / \mathrm{TiO}_{2}$ ETL remains stable during the period of $1000 \mathrm{~s}$. These results indicate that the $0.2 \mathrm{wt} \% \mathrm{Au}-\mathrm{TiO}_{2} / \mathrm{TiO}_{2} \mathrm{ETL}$ contributes to the enhanced device light-soaking stability. The enhancement of photovoltaic performance and device lightsoaking stability rely on multiple factors, including efficient interfacial charge transport, low charge recombination loss, and the additional photocurrent due to LSPR-induced direct transfer of hot electrons, ${ }^{44}$ all of which can attribute to effects of the $\mathrm{Au}-\mathrm{TiO}_{2}$ interface layer.

3.5. Flexible Devices. Our low-temperature solutionbased approach allows the $0.2 \mathrm{wt} \% \mathrm{Au}-\mathrm{TiO}_{2} / \mathrm{TiO}_{2}$ ETL to be fabricated on mechanically flexible ITO/PEN substrates. Figure $4 \mathrm{~d}$ shows the champion $J-V$ curves of the flexible devices. The flexible 0.2 wt $\% \mathrm{Au}-\mathrm{TiO}_{2} / \mathrm{TiO}_{2} \mathrm{PSCs}$ exhibit considerably low hysteresis indices (0.19) while showing a PCE of $15.36 \%$, which shows a significant improvement compared to the control device (hysteresis index $=0.31$, PCE $=12.80 \%$ ), as shown in Table S3. Detailed photovoltaic parameters of 10 flexible devices are shown in Figure S10, indicating reproducible enhancement in the performance of flexible PSCs via the incorporation of $\mathrm{Au}$ NPs into the $\mathrm{TiO}_{2}$ layers, as discussed above. The inset of Figure $4 \mathrm{~d}$ shows a prototype of flexible PSCs bending freely.

\section{CONCLUSIONS}

In conclusion, we have developed a dual ETL with embedded plasmonic nanostructures for rigid and flexible PSCs with high efficiency achieved. Such a dual ETL is fabricated via a lowtemperature solution-processed approach. The bottom is a hybrid layer consisting of plasmonic Au NPs embedded in anatase $\mathrm{TiO}_{2}$ films, while the top layer is purely made of nanocrystalline anatase $\mathrm{TiO}_{2} \mathrm{NPs}$, which is indispensable in preventing a direct contact between $\mathrm{Au}$ NPs and the perovskite. The optimized 0.2 wt $\% \mathrm{Au}-\mathrm{TiO}_{2}$ layer greatly benefited the ETL/perovskite interface by stimulating interfacial charge transfer, improving light absorption and inhibiting interfacial charge recombination. Thus, the champion PCEs of PSCs based on 0.2 wt $\% \mathrm{Au}-\mathrm{TiO}_{2} / \mathrm{TiO}_{2}$
ETLs were 20.31 and $15.36 \%$ on rigid and flexible substrates, respectively. This research provides a facile route for the design of flexible PSCs with high performance in a scalable fashion.

\section{ASSOCIATED CONTENT}

\section{Supporting Information}

The Supporting Information is available free of charge at https://pubs.acs.org/doi/10.1021/acsaem.0c00276.

Photovoltaic parameters of the PSCs based on different concentrations of $\mathrm{Au}-\mathrm{TiO}_{2}$ dual ETLs; photovoltaic parameters of the PSCs based on selected ETLs; photovoltaic parameters of the flexible PSCs; schematic of plasmon-induced charge separation; $J-V$ curves of samples based on the configuration of ITO/ETL/Ag; high-resolution TEM characterization; UV-vis transmittance characterization; $J-V$ curves of PSCs based on different concentrations of $\mathrm{Au}-\mathrm{TiO}_{2} / \mathrm{TiO}_{2}$ dual ETLs; $J-V$ curves of PSCs based on selected ETLs; statistical deviation of the photovoltaic parameters of the PSCs based on different concentrations of $\mathrm{Au}-\mathrm{TiO}_{2} / \mathrm{TiO}_{2}$ ETLs; top view SEM characterization; UV-vis absorption characterization; and statistical photovoltaic parameters of flexible PSCs (PDF)

\section{AUTHOR INFORMATION}

\section{Corresponding Authors}

Tung-Chun Lee - Department of Chemistry and Institute for Materials Discovery, University College London (UCL), London

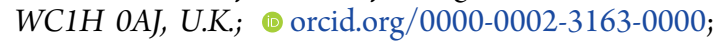

Email: tungchun.lee@ucl.ac.uk

Da-Qin Yun - College of Energy, Xiamen University, Xiamen 361005, China; ○ orcid.org/0000-0003-1667-8417;

Email: dqyun@xmu.edu.cn

\section{Authors}

Da-Wei Zhao - College of Energy, Xiamen University, Xiamen 361005, China

Ming-Yu Yu - College of Energy, Xiamen University, Xiamen 361005, China

Ling-Ling Zheng - College of Energy, Xiamen University, Xiamen 361005, China; @ orcid.org/0000-0001-7333-2768

Ming Li - College of Energy, Xiamen University, Xiamen 361005, China

Shi-Jie Dai - College of Energy, Xiamen University, Xiamen 361005, China

Di-Chun Chen - Xiamen Branch of Luoyang Ship Material Research Institute, Xiamen 361006, China

Complete contact information is available at:

https://pubs.acs.org/10.1021/acsaem.0c00276

\section{Author Contributions}

"D.-W.Z., M.-Y.Y. and L.-L.Z. contributed equally to this work. Notes

The authors declare no competing financial interest.

\section{ACKNOWLEDGMENTS}

This work was supported by the Youth Program of the National Natural Science Foundation of China (no. 61605164), the Development Funds from the College of Energy at Xiamen University (2018NYFZ05), as well as the UCL BEAMS Future Leader Award from the EPSRC 2016 Institutional Sponsorship Award (EP/P511262/1). The EQE 
characterization was performed under the assistance of Nanfeng Zheng.

\section{REFERENCES}

(1) Li, Z.; Klein, T. R.; Kim, D. H.; Yang, M. J.; Berry, J. J.; van Hest, M. F. A. M.; Zhu, K. Scalable Fabrication of Perovskite Solar Cells. Nat. Rev. Mater. 2018, 3, 18017.

(2) NREL Research Cell Record Efficiency Chart. https://www.nrel. gov/pv/assets/pdfs/best-research-cell-efficiencies.20190923.pdf (accessed 2019).

(3) Cheacharoen, R.; Rolston, N.; Harwood, D.; Bush, K. A.; Dauskardt, R. H.; McGehee, M. D. Design and Understanding of Encapsulated Perovskite Solar Cells to Withstand Temperature Cycling. Energy Environ. Sci. 2018, 11, 144-150.

(4) Rong, Y.; Hu, Y.; Mei, A.; Tan, H.; Saidaminov, M. I.; Seok, S. I.; McGehee, M. D.; Sargent, E. H.; Han, H. Challenges for Commercializing Perovskite Solar Cells. Science 2018, 361, No. eaat8235.

(5) Domanski, K.; Alharbi, E. A.; Hagfeldt, A.; Grätzel, M.; Tress, W. Systematic Investigation of the Impact of Operation Conditions on the Degradation Behaviour of Perovskite Solar Cells. Nat. Energy 2018, 3, 61-67.

(6) Correa-Baena, J.-P.; Saliba, M.; Buonassisi, T.; Grätzel, M.; Abate, A.; Tress, W.; Hagfeldt, A. Promises and Challenges of Perovskite Solar Cells. Science 2017, 358, 739-744.

(7) Christians, J. A.; Habisreutinger, S. N.; Berry, J. J.; Luther, J. M. Stability in Perovskite Photovoltaics: A Paradigm for Newfangled Technologies. ACS Energy Lett. 2018, 3, 2136-2143.

(8) Wang, Z.; Lin, Q. Q.; Chmiel, F. P.; Sakai, N.; Herz, L. M.; Snaith, H. J. Efficient Ambient-Air-Stable Solar Cells with 2D-3D Heterostructured Butylammonium-Caesium-Formamidinium Lead Halide Perovskites. Nat. Energy 2017, 2, 17135.

(9) Xiao, Z.; Yan, Y. Progress in Theoretical Study of Metal Halide Perovskite Solar Cell Materials. Adv. Energy Mater. 2017, 7, 1701136.

(10) Zhou, Z.; Pang, S.; Liu, Z.; Xu, H.; Cui, G. Interface Engineering for High-Performance Perovskite Hybrid Solar Cells. J. Mater. Chem. A 2015, 3, 19205-19217.

(11) Lopez-Varo, P.; Jiménez-Tejada, J. A.; García-Rosell, M.; Ravishankar, S.; Garcia-Belmonte, G.; Bisquert, J.; Almora, O. Device Physics of Hybrid Perovskite Solar Cells: Theory and Experiment. Adv. Energy Mater. 2018, 8, 1702772.

(12) Christians, J. A.; Schulz, P.; Tinkham, J. S.; Schloemer, T. H.; Harvey, S. P.; Tremolet de Villers, B. J.; Berry, J. J.; Luther, J. M.; Luther, J. M. Tailored interfaces of unencapsulated perovskite solar cells for $>1,000$ hour operational stability. Nat. Energy 2018, 3, 6874

(13) Yuan, Y.; Huang, J. Ion Migration in Organometal Trihalide Perovskite and Its Impact on Photovoltaic Efficiency and Stability. Acc. Chem. Res. 2016, 49, 286-293.

(14) Walsh, A.; Stranks, S. D. Taking Control of Ion Transport in Halide Perovskite Solar Cells. ACS Energy Lett 2018, 3, 1983-1990.

(15) Bag, M.; Renna, L. A.; Adhikari, R. Y.; Karak, S.; Liu, F.; Lahti, P. M.; Russell, T. P.; Tuominen, M. T.; Venkataraman, D. Kinetics of Ion Transport in Perovskite Active Layers and Its Implications for Active Layer Stability. J. Am. Chem. Soc. 2015, 137, 13130-13137.

(16) Zhou, Y.-Q.; Wu, B.-S.; Lin, G.-H.; Xing, Z.; Li, S.-H.; Deng, L.L.; Chen, D.-C.; Yun, D.-Q.; Xie, S.-Y. Interfacing Pristine C-60 onto $\mathrm{TiO}_{2}$ for Viable Flexibility in Perovskite Solar Cells by a LowTemperature All-Solution Process. Adv. Energy Mater. 2018, 8, 1800399.

(17) Yang, D.; Yang, R. X.; Wang, K.; Wu, C. C.; Zhu, X. J.; Feng, J. S.; Ren, X. D.; Fang, G. J.; Priya, S.; Liu, S. Z. High Efficiency PlanarType Perovskite Solar Cells with Negligible Hysteresis Using EDTAComplexed $\mathrm{SnO}_{2}$. Nat. Commun. 2018, 9, 3239.

(18) Arora, N.; Dar, M. I.; Hinderhofer, A.; Pellet, N.; Schreiber, F.; Zakeeruddin, S. M.; Grätzel, M. Perovskite solar cells with CuSCN hole extraction layers yield stabilized efficiencies greater than $20 \%$. Science 2017, 358, 768-771.
(19) Back, H.; Kim, G.; Kim, J.; Kong, J.; Kim, T. K.; Kang, H.; Kim, H.; Lee, J.; Lee, S.; Lee, K. Achieving Long-Term Stable Perovskite Solar Cells via Ion Neutralization. Energy Environ. Sci. 2016, 9, 12581263.

(20) Chan, K.; Wright, M.; Elumalai, N.; Uddin, A.; Pillai, S. Plasmonics in Organic and Perovskite Solar Cells: Optical and Electrical Effects. Adv. Opt. Mater. 2017, 5, 1600698.

(21) Clavero, C. Plasmon-Induced Hot-Electron Generation at Nanoparticle/Metal-Oxide Interfaces for Photovoltaic and Photocatalytic Devices. Nat. Photonics 2014, 8, 95-103.

(22) Ye, M.; Hong, X.; Zhang, F.; Liu, X. Recent Advancements in Perovskite Solar Cells: Flexibility, Stability and Large Scale. J. Mater. Chem. A 2016, 4, 6755-6771.

(23) Mayer, K. M.; Hafner, J. H. Localized Surface Plasmon Resonance Sensors. Chem. Rev. 2011, 111, 3828-3857.

(24) Jang, Y. H.; Jang, Y. J.; Kim, S.; Quan, L. N.; Chung, K.; Kim, D. H. Plasmonic Solar Cells: From Rational Design to Mechanism Overview. Chem. Rev. 2016, 116, 14982-15034.

(25) Zhang, W.; Saliba, M.; Stranks, S. D.; Sun, Y.; Shi, X.; Wiesner, U.; Snaith, H. J. Enhancement of Perovskite-Based Solar Cells Employing Core-Shell Metal Nanoparticles. Nano Lett. 2013, 13, $4505-4510$

(26) Chandrasekhar, P. S.; Dubey, A.; Reza, K. M.; Hasan, M. D. N.; Bahrami, B.; Komarala, V. K.; Hoefelmeyer, J. D.; He, Q.; Wu, F.; Qiao, H.; Zhang, W.-H.; Qiao, Q. Higher Efficiency Perovskite Solar Cells Using Au@SiO ${ }_{2}$ Core-Shell Nanoparticles. Sustainable Energy Fuels 2018, 2, 2260-2267.

(27) Qi, F.; Wang, C.; Cheng, N.; Liu, P.; Xiao, Y.; Li, F.; Sun, X.; Liu, W.; Guo, S.; Zhao, X.-Z. Improving the Performance through SPR Effect by Employing $\mathrm{Au@SiO2} \mathrm{Core-Shell} \mathrm{Nanoparticles}$ Incorporated $\mathrm{TiO}_{2}$ Scaffold in Efficient Hole Transport Material Free Perovskite Solar Cells. Electrochim. Acta 2018, 282, 10-15.

(28) Yuan, Z.; Wu, Z.; Bai, S.; Xia, Z.; Xu, W.; Song, T.; Wu, H.; Xu, L.; Si, J.; Jin, Y.; Sun, B. Hot-Electron Injection in a Sandwiched TiOx-Au-TiOxStructure for High-Performance Planar Perovskite Solar Cells. Adv. Energy Mater. 2015, 5, 1500038.

(29) Luo, Q.; Zhang, C.; Deng, X.; Zhu, H.; Li, Z.; Wang, Z.; Chen, X.; Huang, S. Plasmonic Effects of Metallic Nanoparticles on Enhancing Performance of Perovskite Solar Cells. ACS Appl. Mater. Interfaces 2017, 9, 34821-34832.

(30) Fan, R.; Wang, L.; Chen, Y.; Zheng, G.; Li, L.; Li, Z.; Zhou, H. Tailored $\mathrm{Au} @ \mathrm{TiO}_{2}$ Nanostructures for the Plasmonic Effect in Planar Perovskite Solar Cells. J. Mater. Chem. A 2017, 5, 12034-12042.

(31) Zhang, C.; Luo, Q.; Shi, J.; Yue, L.; Wang, Z.; Chen, X.; Huang, S. Efficient Perovskite Solar Cells by Combination Use of $\mathrm{Au}$ Nanoparticles and Insulating Metal Oxide. Nanoscale 2017, 9, 28522864.

(32) Furube, A.; Du, L.; Hara, K.; Katoh, R.; Tachiya, M. Ultrafast Plasmon-Induced Electron Transfer From Gold Nanodots into $\mathrm{TiO}_{2}$ Nanoparticles. J. Am. Chem. Soc. 2007, 129, 14852.

(33) Barbe, C. J.; Arendse, F.; Comte, P.; Jirousek, M.; Lenzmann, F.; Shklover, V.; Gratzel, M. Nanocrystalline Titanium Oxide Electrodes for Photovoltaic Applications. J. Am. Ceram. Soc. 1997, $80,3157-3171$.

(34) Bastús, N. G.; Comenge, J.; Puntes, V. Kinetically Controlled Seeded Growth Synthesis of Citrate-Stabilized Gold Nanoparticles of up to $200 \mathrm{~nm}$ : Size Focusing versus Ostwald Ripening. Langmuir 2011, 27, 11098-11105.

(35) Yang, W. S.; Noh, J. H.; Jeon, N. J.; Kim, Y. C.; Ryu, S.; Seo, J.; Seok, S. I. High-Performance Photovoltaic Perovskite Layers Fabricated Through Intramolecular Exchange. Science 2015, 348, 1234-1237.

(36) Eperon, G. E.; Stranks, S. D.; Menelaou, C.; Johnston, M. B.; Herz, L. M.; Snaith, H. J. Formamidinium Lead Trihalide: A Broadly Tunable Perovskite for Efficient Planar Heterojunction Solar Cells. Energy Environ. Sci. 2014, 7, 982-988.

(37) Kim, H.-S.; Park, N.-G. Parameters AffectingI-VHysteresis of CH3NH3PbI3Perovskite Solar Cells: Effects of Perovskite Crystal 
Size and Mesoporous TiO2Layer. J. Phys. Chem. Lett. 2014, 5, 29272934.

(38) Liang, Z.; Sun, J.; Jiang, Y.; Jiang, L.; Chen, X. Plasmonic Enhanced Optoelectronic Devices. Plasmonics 2014, 9, 859-866.

(39) Xiao, Y.; Cheng, N.; Kondamareddy, K. K.; Wang, C.; Liu, P.; Guo, S.; Zhao, X.-Z. W-Doped $\mathrm{TiO}_{2}$ Mesoporous Electron Transport Layer for Efficient Hole Transport Material Free Perovskite Solar Cells Employing Carbon Counter Electrodes. J. Power Sources 2017, 342, 489-494.

(40) Xiao, Y.; Wang, C.; Kondamareddy, K. K.; Liu, P.; Qi, F.; Zhang, H.; Guo, S.; Zhao, X.-Z. Enhancing the Performance of HoleConductor Free Carbon-Based Perovskite Solar Cells Through RutilePhase Passivation of Anatase $\mathrm{TiO}_{2}$ Scaffold. J. Power Sources 2019, 422, 138-144.

(41) Zhang, J.; Zhao, B.; Linghui, M.; Hongying, W.; Xudong, W.; Chenxi, L. Controlled Synthesis of Gold Nanospheres and Single Crystals in Hydrogel. J. Nanopart. Res. 2007, 9, 1167-1171.

(42) Ginsburg, A.; Priel, M.; Barad, H. N.; Keller, D. A.; Borvick, E.; Rietwyk, K.; Kama, A.; Meir, S.; Anderson, A. Y.; Zaban, A. Solid State ITO Vertical Bar Au-NPs Vertical Bar $\mathrm{TiO}_{2}$ Plasmonic Based Solar Cells. Sol. Energy Mater. Sol. Cells 2018, 179, 254-259.

(43) Chan, K.; Wright, M.; Elumalai, N.; Uddin, A.; Pillai, S. Plasmonics in Organic and Perovskite Solar Cells: Optical and Electrical Effects. Adv. Opt. Mater. 2017, 5, 1600698.

(44) Mali, S. S.; Shim, C. S.; Kim, H.; Patil, P. S.; Hong, C. K. In Situ Processed Gold Nanoparticle-Embedded $\mathrm{TiO}_{2}$ Nanofibers Enabling Plasmonic Perovskite Solar Cells to Exceed 14\% Conversion Efficiency. Nanoscale 2016, 8, 2664-2677.

(45) Yang, D.; Yang, R.; Zhang, J.; Yang, Z.; Liu, S.; Li, C. High Efficiency Flexible Perovskite Solar Cells Using Superior Low Temperature $\mathrm{TiO}_{2}$. Energy Environ. Sci. 2015, 8, 3208-3214.

(46) Feng, J.; Yang, Z.; Yang, D.; Ren, X.; Zhu, X.; Jin, Z.; Zi, W.; Wei, Q.; Liu, S. E-Beam Evaporated $\mathrm{Nb}_{2} \mathrm{O}_{5}$ as An Effective Electron Transport Layer for Large Flexible Perovskite Solar Cells. Nano Energy 2017, 36, 1-8. 